DIPARTIMENTO DI ECONOMIA

\title{
Student Time Allochtion And Educational Production Functions
}

Massimiliano Bratti and Stefano Staffolani

QUADERNI DI RICERCA n. 170

30th July 2002 
Comitato scientifico:

Renato Balducci

Marco Crivellini

Marco Gallegati

Alessandro Sterlacchini

Alberto Zazzaro 


\begin{abstract}
In this paper we aim to remedy some shortcomings in the economic literature on university student absenteeism and academic performance. We start by introducing a simple theoretical model in which students decide the optimal allocation of their time between lecture attendance, self-study and leisure. Under some specific assumptions, we find a positive relationship between lecture attendance and time devoted to self-study in each course, from which we infer that estimates of student performance regressions which omit self-study might be biased. Thus, we estimate an academic performance regression using data from first year undergraduate students of economics in the academic year 1998-99 at the University of Ancona (Italy) and find evidence that once self-study time is controlled for, the positive and significant effect of lecture attendance for some courses disappears. This is likely to be important especially when student performance regressions are used to evaluate the effectiveness of course attendance and to inform the debate on the introduction of mandatory attendance on some courses to enhance student performance.
\end{abstract}

JEL Class.: I21

Keywords: course attendance, student performance, time allocation

Indirizzo: Massimiliano Bratti, Dipartimento di Economia, Università degli Studi di Ancona, Piazzale Martelli 8, 60121 Ancona, Italy (massib@dea.unian.it).

Stefano Staffolani: Dipartimento di Economia, Università degli Studi di Ancona, Piazzale Martelli 8, 60121 Ancona, Italy (staffolani@dea.unian.it). Fax: 0039071 2207102, telephone: 00390712207090. 



\title{
Student Time Allocation and Educational Production Functions*
}

\author{
Massimiliano Bratti and Stefano Staffolani
}

\section{Introduction}

The methodology commonly used by educational economists to analyze student performance is the so-called educational production function. However, different authors have focused on different aspects. In particular, it is possible to distinguish two main ways of interpreting educational production functions. Some researchers are mainly interested in the effect on student performance of the characteristics of educational institutions (mainly primary and secondary schools), which include class size, teacher-student ratios, expenditure per student, differences between public and private institutions ${ }^{1}$ In those studies students are usually treated as the 'raw material' that educational institutions transform into the final product and they are given a completely passive role. On the other side there are studies focusing on student behaviour, namely student time allocation, and its effect on academic performance. The present paper is mainly concerned with this second stream of the economic literature.

We believe that the study of student time allocation and the assessment of the effect of class attendance and self-study on academic performance are of interest to a number of individuals.

Students are certainly interested in knowing what allocation of time is more productive, in the sense of ensuring the highest academic performance, and the amount of work required to pass a certain exam or to graduate in a subject.

\footnotetext{
* Paper to be presented at the XIV annual conference of the European Association of Labour Economists (Paris, 19-22 September 2002) and at the XVII annual conference of the Associazione Italiana degli Economisti del Lavoro (Salerno, 27-27 September 2002). We would like to thank participants at seminars at the University of Ancona, at the annual conference of the Association Française des Sciences Economiques (16-17 May 2002, Lyon) and Roberto Esposti for useful suggestions. The usual disclaimer applies.

${ }^{1}$ See for instance Lazear (2001) for an analysis of the effect of class size and Pritchett and Filmer (1999) for some evidence on educational expenditures.
} 
Educational institutions may obtain useful insights for several reasons. Firstly, they can decide on the number of credits to be attributed to individual courses, according to the workload that each of them requires of students. Secondly, they can evaluate the optimal lecturing time for each course. Thirdly, they can investigate factors affecting student performance. This may also be useful for student selection procedures, so that students with higher prospective academic performance are selected.

Last but not least, the government and the taxpayers may be interested in the efficient and effective allocation of public expenditure (e.g. is it worth increasing the number of teaching staff, or financing longer teaching hours?) and in the ranking of institutions according to student performance. ${ }^{2}$

In this paper, we account for the potential endogeneity of student time allocation and study the effect of self-study time and lecture attendance time on the academic performance of first year undergraduate students of economics.

The paper outline is as follows: the next section reviews the empirical literature on student time allocation and academic performance; section three introduces a simple theoretical model of student time allocation and academic performance. Section four presents the empirical analysis and section five concludes.

\section{Previous literature}

After about nine years since the publication of Romer (1993), who observed a strong positive correlation between students' class attendance and academic performance, and a number of other studies partly in response to and partly motivated by Romer's findings, we were surprised by the relative absence in the economic literature of theoretical and empirical models studying educational performance from the students' side, that is, starting from analysis of student time allocation and assessing its effect on academic performance.

We believe that standard economic theory is able to offer useful insights into student behaviour, the learning process and the effect of policy interventions, such as the introduction of a mandatory attendance policy.

We start with a brief summary of some related literature on student time allocation and academic performance.

\footnotetext{
${ }^{2}$ For instance, the Performance Indicators Steering Group (PISG), established in 1997 in the UK with the primary aim of constructing Performance Indicators (PIs) for the UK university system, regularly produces on a regular basis PIs based on student progression and degree outcomes (see HEFCE 1999).
} 
Schmidt (1983) uses data from an experiment run in the fall of 1970 at the University of Wisconsin-Madison in the Macroeconomics Principles course. His data set includes 216 students and provides a wealth of information concerning student allocation of time. Schmidt estimates a Cobb-Douglas educational production function using both OLS and Full Information Maximum Likelihood (FIML). Using OLS he finds an elasticity of performance with respect to hours of class attendance of 0.215 and of study hours of 0.017 . Therefore hours spent attending lectures are far more productive than hours spent studying at home. He then uses FIML and a latent variable approach (in which time and ability are treated as unobservable or latent variables), which takes account of possible simultaneity between performance and student time allocation (and the endogeneity of lecture attendance and study hours), finding that the productivity of study hours is slightly lower than that of lecture attendance (i.e. a $0.348 \%$ increase in study hours produces the same gain of performance as does increasing lecture attendance by $0.480 \%$ ).

Romer (1993) uses data from three U.S. schools classified by the Barron's Profiles of American Colleges (1991 edition) as 'highly competitive', the second highest of six categories, and on Intermediate Macroeconomics courses (the full sample size is 195 individuals). Romer recognizes that attendance is endogenous and that his analysis cannot isolate the causal impact of class attendance on learning and performance, although he believes that it can provide 'some suggestive evidence' (p. 171). The author runs regressions of student performance in level on fraction of lectures attended, both excluding and including some proxies for motivation. The effect of class attendance is always positive and significant; however, its magnitude is greatly reduced by the inclusion of proxies for motivation. ${ }^{3}$ In the light of this evidence Romer suggests that perhaps a policy of mandatory attendance might enhance student academic performance.

Durden and Ellis (1995) use data on a Principles of Economics course taught at a medium-size, comprehensive state university (the sample includes 346 students). The authors find, using OLS, that 'the typical student is not adversely affected by a few absences... but excessive absenteeism is associated strongly with poor academic performance' (p. 345) and that measures of student motivation or prior educational performance are the most important determinants of student performance.

Devadoss and Foltz (1996) use data from the University of Idaho, Washington State University, Purdue University and Ohio State University, on Agricultural Economics classes for about 400 students. Using seemingly unrelated regression (SUR) techniques, in order to take into account the simul-

\footnotetext{
${ }^{3}$ Which might be correlated also with study time.
} 
taneity of class attendance and class performance, they find that motivation positively affects attendance and attendance positively affects class performance. According to their results hours of study have a negative impact on student performance. This finding may be somewhat surprising, however the authors consider in their model hours of study as exogenous.

Chan, Shum and Wright (1997) use data on students in two sections of a Principles of Finance course at a Mid-Western, regional, state university (the full sample comprises 71 individuals). The authors use both Tobit and Heckman two-stage procedures in order to take account of the students' survival process in the course. They find a significant positive relationship between attendance and student performance in the Tobit model and a insignificant relationship using Heckman selection procedure. Moreover, a mandatory attendance policy appears not to improve performance.

Dolton, Marcenaro and Navarro (2001) use data from the University of Malaga drawn from a survey conducted in April 1999 on first and final year students. Their sample includes 3722 observations taken from students from forty different subject areas. They find that lectures are four times more productive than self-study in the linear specification of the stochastic educational performance while in the Cobb-Douglas specification the elasticity of performance with respect to lecture attendance is twice than that of study time (on average 0.02 and 0.01 respectively). It is worth noting that their estimates may be affected by selection bias since data were collected during a class. The authors address the problem of the potential endogenity of pre-university performance but neglect that of student time allocation.

Therefore, the findings of this literature do not seem to be uncontroversial. In particular, by focusing on studies of class attendance and student performance omitting student self-study, the estimates are likely to be biased. In fact, there may be several sources of correlation between hours of lectures attended and hours studied, such as students' motivation or the preference for leisure, which cannot be controlled for perfectly. This suggests that the effect of student absenteeism on student performance estimated from educational production functions omitting student self-study is likely to be upward biased. This is also the reason why one should be very careful in obtaining counterfactuals on the effect of mandatory attendance policies from those models. In particular, what will the reaction of students be to a mandatory attendance policy? Will they maintain the same hours of self-study or will they reduce (or increase) them? Will their academic performance be increased or not? Secondly, even in models which include both hours of lecture attendance and hours of study some factors may affect both student time allocation and academic performance, so that there are likely to be simultaneity problems. 
In light of these considerations, in this paper we aim to remedy some shortcoming in the existing literature by modeling theoretically and estimating empirically the process of student time allocation between alternative uses and the effect of class attendance and self-study on student university performance. In our framework both hours of study and class attendance are endogenous variables, whose optimal values are the outcome of the utility maximizing behaviour of 'rational students'.

\section{A simple model of student behaviour and student academic performance}

We analyze an individual who has decided to undertake higher education in order to obtain a degree in a given subject in a certain number of years, namely the course's legal duration, ${ }^{4}$ which we normalize to one (first period).$^{5}$ After graduation, in the second period the individual starts working. To simplify the notation here we drop the index for the individuals, although all the parameters and the exogenous variables of the model are likely to differ across students, introducing individual heterogeneity. We suppose that the student's utility can be defined as:

$$
U=u\left(c_{1}, \ell_{1}\right)+\beta u\left(c_{2}, \ell_{2}\right)
$$

where:

1. $\beta$ depends on the relative duration of working life with respect to the period devoted to higher education ${ }^{6}$ and on the discount rate;

2. $\ell_{1}=1-\sum_{i=1}^{N}\left(s_{i}+\gamma a_{i}\right)$ is leisure time in the first period, with $s_{i}$ denoting time devoted to self-study and $a_{i}$ time devoted to course attendance in

\footnotetext{
${ }^{4}$ We assume here that the expected duration of the course is exogenous and equal across individuals. This assumption may not be too strong during the first year of enrollment (analyzed in the empirical work) before students take university exams. However, after taking some exams and observing the results it is likely that students will revise their expectations about the time required to graduate. According to our simplifying assumption students with different levels of ability have different expected grades but an equal expected course duration at enrollment.

${ }^{5}$ We do not address here the issues of the decision to enroll in higher education or that of the university subject. For a detailed analysis of the former in the case of Italy see for instance Gambetta (1987) while for an analysis of the latter for the same country see Bratti and Staffolani (2001).

${ }^{6}$ The utility function could have been written as: $U=H u\left(c_{1}, \ell_{1}\right)+(T-H) \rho u\left(c_{2}, \ell_{2}\right)$ where $H$ is the legal duration of the university course, $T$ the end of the planning horizon and $\rho$ the discount rate. Dividing by $H$ and defining $\beta \equiv \frac{(T-H)}{H} \rho$ we obtain equation (1).
} 
the course $i ; N$ is the total number of exams to be passed and $\gamma>1$ is a coefficient which takes account of the fact that $\gamma a_{i}$ hours are necessary to produce $a_{i}$ hours of lecture attendance and depends on travel times;

3. $\ell_{2}=\bar{\ell}_{2}$ is leisure time in the second period, which we assume to be exogenous. ${ }^{7}$ Hence $\left(1-\bar{\ell}_{2}\right)$ is the exogenous labour supply in the second period;

4. $c_{1}=\bar{c}_{1}$ is first period consumption which is equal to exogenous revenue from the family or the institutions (such as scholarships) net of the cost of education during the period of study; ${ }^{8}$

5. $c_{2}$ is second period consumption; we assume that it depends on labor income only and that the graduate wage is an increasing concave function $g$ of the grades earned in individual exams $\left(G_{i}\right)$; we assume that $c_{2}=w g\left(1-\overline{\ell_{2}}\right)$, where $w$ is the non-graduate wage and $g$ a sort of mark-up due to university performance.

To simplify notation in the equations we have dropped the index for the individual. We consider the grades $\left(G_{i}\right)$ earned in the exams to be an indicator of academic performance and define $g$ as follows:

$$
g=g\left(G_{1}, G_{2}, \ldots, G_{N}\right)=\sum_{i} \ln \left(G_{i}\right)
$$

This formulation simplifies the model, is coherent with the hypothesis of an increasing concave relationship between wage and grade earned in the single exams and allows us to obtain some predictions which will be tested in the empirical analysis.

The grade earned in each of the exams is a function of the time devoted to self-study, of the time spent attending lectures and of unobserved individual ability $\left(e_{i}\right): G_{i}=G\left(s_{i}, a_{i}\right) e_{i}$. We assume that $e_{i}$ is log-normally (i.e. asymmetrically) distributed with mean zero. Consumption in the second period is therefore given by:

$$
c_{2}=w \sum_{i} \ln \left(G\left(s_{i}, a_{i}\right) e_{i}\right)\left(1-\overline{\ell_{2}}\right)
$$

Each student maximizes the expected utility of equation (1) subject to the first period time constraint (see point 2) and the budget constraint in

\footnotetext{
${ }^{7}$ This is coherent with a labor market with institutional constraints on working hours.

${ }^{8}$ Since we are mainly interested in full-time students, we neglect work activity in the first period. Hence, assuming that students cannot borrow against their future incomes first period consumption is exogenous.
} 
the second period (see equation (2)):

$\max _{s_{i}, a_{i}} E_{0}\left[u\left(\bar{c}_{1}, 1-\sum_{i}\left(s_{i}+\gamma a_{i}\right)\right)+\beta u\left(w \sum_{i} \ln \left(G_{i}\left(s_{i}, a_{i}\right) e_{i}\right)\left(1-\bar{\ell}_{2}\right), \bar{\ell}_{2}\right)\right]$

where $E_{0}[$.$] is the expectation operator at time 0$, i.e. at university enrollment. In what follows we drop the time index. The choice variables are the study time $s_{i}$ and the course attendance time $a_{i}$ in the $N$ courses.

Using the first period time constraint it turns out that $u_{a_{i}}^{\prime}=u_{a_{j}}^{\prime}=-\gamma u_{\ell_{1}}^{\prime}$ and $u_{s_{i}}^{\prime}=u_{s_{j}}^{\prime}=-u_{\ell_{1}}^{\prime}$, for every $i, j$, (where $u^{\prime}$ indicates first derivative). The FOC's of the problem are in the case of an interior optimum:

$$
\begin{gathered}
u_{\ell_{1}}^{\prime}=\theta E\left(u_{c_{2}}^{\prime}\right) \frac{G_{s_{i}}^{\prime}}{G_{i}} \quad \text { for } \quad i=1 \ldots N \\
\gamma u_{\ell_{1}}^{\prime}=\theta E\left(u_{c_{2}}^{\prime}\right) \frac{G_{a_{i}}^{\prime}}{G_{i}} \quad \text { for } \quad i=1 \ldots N
\end{gathered}
$$

where we defined $\theta \equiv \beta w\left(1-\bar{\ell}_{2}\right) . u_{c_{2}}^{\prime}$ indicates the first derivative of second period utility with respect to consumption and $G_{s_{i}}^{\prime}, G_{a_{i}}^{\prime}$ are first derivatives of grade in exam $i$ with respect to self-study and lecture attendance, respectively.

This is a system of $2 N$ equations in $2 N$ unknown variables. In what follows we suppose that the grade earned in course $i$ is a constant elasticity function of its arguments, course attendance and self-study. The elasticities are denoted with $\varepsilon_{a_{i}}$ and $\varepsilon_{s_{i}}$, respectively. In particular, we assume a CobbDouglas relationship between grade earned in course $i$, time devoted to study and time devoted to course attendance, i.e. $G_{i}=z_{i} s_{i}^{\varepsilon_{s_{i}}} a_{i}^{\varepsilon_{a_{i}}} e_{i}$, where $z_{i}$ is a course specific scale parameter. The Cobb-Douglas ${ }^{9}$ is a popular specification in the empirical literature ${ }^{10}$ and the main reason for choosing it is to obtain theoretical implications that can be applied to the existing empirical literature. The specification can be generalized to include also person specific attributes such as individual ability or pre-university exam scores (which are considered in the empirical specification).

The previous system can be written as:

$$
\begin{gathered}
s_{i} u_{\ell_{1}}^{\prime}=\theta E\left(u_{c_{2}}^{\prime}\right) \varepsilon_{s_{i}} \quad \text { for } \quad i=1 \ldots N \\
\gamma a_{i} u_{\ell_{1}}^{\prime}=\theta E\left(u_{c_{2}}^{\prime}\right) \varepsilon_{a_{i}} \quad \text { for } \quad i=1 \ldots N
\end{gathered}
$$

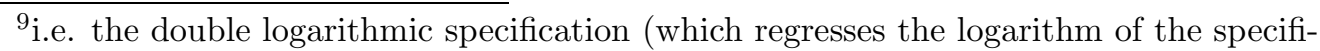
cation on the logarithm of the inputs).

${ }^{10}$ See for instance Allison (1982), Chizmar and Zak (1984), Schimdt (1983) or Dolton et al. (2001).
} 
hence: $s_{i}^{*}=\frac{\varepsilon_{s_{i}}}{\varepsilon_{s_{j}^{*}}^{*}} s_{j}^{*}$ and $a_{i}^{*}=\frac{\varepsilon_{a_{i}}}{\varepsilon_{a_{j}}} a_{j}^{*}$, so that

$$
a_{i}^{*}=\frac{1}{\gamma} \frac{\varepsilon_{a_{i}}}{\varepsilon_{s_{i}}} s_{i}^{*}
$$

i.e. if $\varepsilon_{a_{i}}>0$ and $\varepsilon_{s_{i}}>0, a_{i}$ and $s_{i}$ are positively related ${ }^{11}$. Once account is taken of travel times to attend courses, the optimal ratio between time devoted to course attendance and time devoted to self-study is given by the ratio between the grade elasticities with respect to the two time inputs.

The ratio between self-study (course attendance) in two different courses must be equal to the ratio between the elasticities of performance to selfstudy (course attendance) in the two courses.

To solve the problem, we sum across all the equations (3) and (4). On the left hand side we find $\sum_{i}\left(s_{i}+\gamma a_{i}\right)$, which is equal to $1-\ell_{1}$. Hence:

$$
u_{\ell_{1}}^{\prime}\left(1-\ell_{1}\right)=\theta E\left(u_{c_{2}}^{\prime}\right) \sum_{i}\left(\varepsilon_{s_{i}}+\varepsilon_{a_{i}}\right)
$$

In order to obtain an explicit solution for the maximization problem, we impose further structure on the problem and suppose that $u_{t}=\kappa c_{t}+\ln \left(\ell_{t}\right)$ for $t=1,2$, so that $u_{\ell_{1}}^{\prime}=\frac{1}{\ell_{1}}$ and $u_{c_{2}}^{\prime}=\kappa$. Therefore we obtain:

the optimal leisure time for the first period

$$
\ell_{1}^{*}=\frac{1}{1+\theta \kappa \sum_{i}\left(\varepsilon_{s_{i}}+\varepsilon_{a_{i}}\right)},
$$

the optimal time to be devoted to self-study

$$
s_{i}^{*}=\frac{\theta \kappa \varepsilon_{s_{i}}}{1+\theta \kappa \sum_{i}\left(\varepsilon_{s_{i}}+\varepsilon_{a_{i}}\right)}
$$

and the optimal time devoted to course attendance

$$
a_{i}^{*}=\frac{\theta \kappa \varepsilon_{a_{i}}}{\gamma\left(1+\theta \kappa \sum_{i}\left(\varepsilon_{s_{i}}+\varepsilon_{a_{i}}\right)\right)}
$$

This result enables us to obtain the value of the logarithm of the grade for each exam:

$$
\ln \left(G_{i}^{*}\right)=\ln \left(z_{i}\right)+\varepsilon_{s_{i}} \ln \left(s_{i}^{*}\right)+\varepsilon_{a_{i}} \ln \left(a_{i}^{*}\right)+\ln \left(e_{i}\right) .
$$

\footnotetext{
${ }^{11}$ This result also holds in the case of a CES specification of the type $G_{i}=$ $z_{i}\left[\phi_{a_{i}} a_{i}^{\rho}+\phi_{s_{i}} s_{i}^{\rho}\right]^{\frac{\mu}{\rho}}$, with $\phi_{a_{i}}, \phi_{s_{i}}>0$. In fact, it turns out that $a_{i}^{*}=\left(\frac{1}{\gamma} \frac{\phi_{a_{i}}}{\phi_{s_{i}}}\right)^{\sigma} s_{i}^{*}$, where $\sigma=\frac{1}{1-\rho}$ is the constant elasticity of substitution between self-study and attendance times. Hence there is complementarity between the two inputs.
} 
Summing across equations we also obtain $g$, our index of overall academic performance:

$$
g=Z+\sum_{i}\left[\varepsilon_{s_{i}} \ln \left(s_{i}^{*}\right)+\varepsilon_{a_{i}} \ln \left(a_{i}^{*}\right)\right]+\sum_{i} \ln \left(e_{i}\right)
$$

where $Z=\sum_{i} \ln \left(z_{i}\right)$. Hence, it straightforwardly follows that in this framework by estimating equation (7) the coefficients of the logarithms of attendance and self-study in a specific course provide the elasticity of the grade earned in the corresponding exam with respect to the same variables. In fact, equation (7) yelds: $\frac{\partial g}{\partial \ln \left(s_{i}^{*}\right)}=\frac{\partial \ln \left(G_{i}^{*}\right)}{\partial \ln \left(s_{i}^{*}\right)}=\varepsilon_{s_{i}}$. An analogous expression holds for hours of course attendance.

Another point that we want to stress is that by replacing the expression for $s_{i}^{*}$ (given by equation 5 ) in the single exam performance regressions (6) we find that:

$$
\ln \left(G_{i}^{*}\right)=\ln \left(z_{i}\right)+\varepsilon_{s_{i}} \ln \left(\gamma \frac{\varepsilon_{s_{i}}}{\varepsilon_{a_{i}}}\right)+\left(\varepsilon_{a_{i}}+\varepsilon_{s_{i}}\right) \ln \left(a_{i}^{*}\right)+\ln \left(e_{i}\right) .
$$

Therefore, in our set-up a regression omitting the time devoted to selfstudy produces an overestimation of the elasticity of performance with respect to time of lecture attendance, the size of the overestimation being the elasticity of performance with respect to self-study time; that is, the coefficient of $a_{i}^{*}$ is the total elasticity of scale ${ }^{12}$.

\section{The empirical analysis}

\subsection{Data Description}

The Faculty of Economics of the University of Ancona (Italy) each year conducts a survey on the quality of its educational delivery. A questionnaire is compiled by students when they apply for the second and the third academic years, in the period between September and October. We analyze the survey conducted in 1999, referring to students applying for their second academic year. Hence, we consider the performance during the first year (October 1998 - October 1999).

Some information on the Italian university system and the University of Ancona may be useful. In Italy, students are not obliged to take exams at the end of courses. In fact, they may take them in some fixed periods

\footnotetext{
${ }^{12}$ This result is robust to the CES specification. In fact, the expression in the case of the CES function (see note 11) is: $\ln \left(G_{i}^{*}\right)=\ln \left(z_{i}\right)+\frac{\mu}{\rho} \ln \left[\left(\frac{\gamma}{\phi_{a_{i}}}\right)^{\frac{\rho}{1-\rho}} \phi_{s_{i}}^{\frac{1}{1-\rho}}\right]+\mu \ln \left(a_{i}^{*}\right)+e_{i}$.
} 
of the year throughout the duration of the degree course. Hence, in our data students have taken a different number of exams and passed a different number of exams in the first year ${ }^{13}$. Furthermore, course attendance is not compulsory.

At the Faculty of Economics of the University of Ancona students should pass 5 exams during the first academic year (Mathematics, Economics, Accounting, Economic History and Law).

The 1999 survey contains data on 411 out of 424 first year students. Students who did not apply for the second year (drop-outs) were interviewed by telephone. We dropped from the sample 33 students who declared that they were working full-time ${ }^{14}$ and a further seven students who did not report data on the type of secondary school attended or the grade obtained in the secondary school final exam. ${ }^{15}$ The final sample comprises 371 individuals.

The survey gathers a wealth of information on individual and family characteristics, such as parent's education, social class and incomes, domicile, grade in the secondary school final exam, etc. The most important items of information concerning student time allocation and performance are the following:

- the percentage of lectures attended by course, in classes;

- the number of hours of self-study by course, in classes;

- the grade eventually earned in each of the course exams. The minimum grade needed to pass an exam is $18 / 30$ while the maximum grade is $30 / 30$ cum laude (codified as 31/30). Moreover, the grade is recorded, and therefore observable, only if the exam is passed.

Some descriptive statistics concerning course attendance (measured as the percentage of courses attended) and self-study are presented in table 1 and 2 , respectively.

On average, students passed 2.62 exams out of the legal 5 of the first academic year. ${ }^{16}$

\footnotetext{
${ }^{13}$ Since we use only information on the first academic year, for some individuals we do not observe the grades in the exams not yet taken, but which will be probably taken later on during the degree course. Therefore, these are censored data.

${ }^{14}$ This was because the theoretical analysis of section 3 considers only full-time students.

${ }^{15}$ These observations were dropped because we consider the two missing variables central to explanation of academic performance. In all the other cases of missing we included a missing value dummy.

${ }^{16}$ This low figure may also depend on the fact that most students filled in the questionnaire before the September-October exam session, which is part of the first academic year.
} 
Table 1: Distribution of \% course attendance (371 obs.), percentages

\begin{tabular}{|lccccc|}
\hline Course & not attended & $0-25 \%$ & $25-50 \%$ & $50-75 \%$ & $75-100 \%$ \\
\hline Law & 7.55 & 19.95 & 9.97 & 15.09 & 47.44 \\
Mathematics & 7.28 & 5.66 & 2.96 & 7.82 & 76.28 \\
Accounting & 8.63 & 11.05 & 4.85 & 10.78 & 64.69 \\
Economics & 8.63 & 8.89 & 4.58 & 7.82 & 70.08 \\
Ec. History & 9.16 & 40.43 & 12.94 & 11.05 & 26.42 \\
\hline
\end{tabular}

Note. The sum by row may not be 100 because of roundings.

Table 2: Distribution of self-study hours (371 obs.), percentages

\begin{tabular}{|lcccccc|}
\hline Course & not studied & $0-99$ & $100-199$ & $200-299$ & $300-399$ & $400+$ \\
\hline Law & 38.81 & 7.28 & 16.44 & 19.68 & 12.67 & 5.12 \\
Mathematics & 33.96 & 13.75 & 20.75 & 18.33 & 9.16 & 4.04 \\
Accounting & 31.81 & 12.67 & 25.07 & 18.33 & 9.7 & 2.43 \\
Economics & 44.2 & 4.85 & 18.6 & 17.25 & 10.51 & 4.58 \\
Ec. History & 53.64 & 16.98 & 16.71 & 8.36 & 2.43 & 1.89 \\
\hline
\end{tabular}

Note. The sum by row may not be 100 because of roundings.

\subsection{Empirical strategy and results}

The theoretical model of section 3 gives us some useful suggestions for the empirical work.

Since, as said, the percentage of lecture attended and self-study time are reported in the survey in categorical form, we first run some interval regressions (see for instance Stewart 1983) and kept the predicted values. ${ }^{17}$ This provided continuous measures of lecture attendance time and self-study time which were then used at a second stage for the estimation of the single exam and the overall educational performance functions for first year students (see equation (7)). ${ }^{18}$ Among the regressors in the interval regressions for lecture attendance and self-study, which are to be interpreted as reduced form models for the optimal demand of the two choice variables, we included: type of motivation for continuing in higher education, parents' education and social class, parents' income, gender, age at enrollment, domicile during the first academic year, grade at secondary school final exam interacted with

\footnotetext{
${ }^{17}$ The predicted values used are those conditioned on the fact the the effective value is observed in a specific interval. We used the intreg STATA command, see the STATA 7 Reference Su-Z manual, pp.186-187 (STATA 2001).

${ }^{18}$ Predicted percentages of lectures attended by course were converted into predicted hours of attendance.
} 
Table 3: Descriptive statistics for predicted attendance and self-study hours by course

\begin{tabular}{|lccc|}
\hline Variable & N. obs. & Mean & Std. Dev. \\
\hline Attendance & & & \\
Law & 371 & 37.60 & 21.35 \\
Mathematics & 371 & 64.31 & 24.17 \\
Accounting & 371 & 58.30 & 27.39 \\
Economics & 371 & 60.47 & 26.78 \\
Ec. History & 371 & 26.25 & 21.05 \\
& & & \\
Self-study & & & \\
Law & 371 & 146.49 & 146.77 \\
Mathematics & 371 & 132.75 & 131.04 \\
Accounting & 371 & 132.77 & 123.47 \\
Economics & 371 & 129.27 & 139.99 \\
Ec. History & 371 & 68.74 & 99.84 \\
\hline
\end{tabular}

type of secondary school and type of secondary school attended. These are the variables which are likely to affect student preferences and the costs and benefits of course attendance and self-study.

Results of the interval regressions are shown in tables A2 and A3 in the appendix. Table A1 reports the variables description. Some descriptive statistics for predicted lecture attendance $(a)$ and self-study $(s)$ for the five courses of the first year are listed in table 3. For the sake of brevity, here we do not comment on the interval regressions results but focus only on the evidence concerning student academic performance.

A first main difference with respect to specifications previously used in the literature is that our educational performance regression does not include both exogenous variables which affect student performance only through their effect on lecture attendance and self-study and endogenous variables (lecture attendance and self-study times), since we believe that such a specification has no theoretical foundation. In fact, we are interested either in the reduced form, i.e. the specification including only exogenous variables, or in the structural form, i.e. the form including only the first determinants of educational performance, both endogenous and exogenous, but excluding variables affecting educational performance via their effect on the endogenous variables or previous secondary school performance only. ${ }^{19} \mathrm{~A}$ second difference is that

\footnotetext{
${ }^{19}$ Monk (1990), for instance, observes that many home and background variables have been included among the inputs into educational production functions without a strong theoretical rationale for their importance (p. 24). The idea of considering the educational
} 
we consider lecture attendance and self-study as endogenous. Our procedure is equivalent to an instrumental variables (IV) estimation, where the identifying instruments are the exogenous variables excluded from the educational performance functions. The exclusion of a wide range of individual or family background variables is motivated by the fact that some of them affect only study and lecture attendance times (such as the geographic residence once controlled for secondary school performance), while other factors, such as the family background, are expected to affect only early school performance (see the life-course hypothesis in Shavit and Blossfeld 1993). However, we estimated also specifications of the exam performance functions including all the variables used in the interval regressions. In general, the likelihood ratio (LR) tests could not reject the null hypothesis of the joint statistical insignificance of the identifying instruments ${ }^{20}$ (since they are likely to affect academic performance only via their impact on choice variables).

It is worth noting that:

- in the theoretical model $s_{i}^{*}$ and $a_{i}^{*}$ are the optimal self-study and lecture attendance times allocated to the single courses along the degree course duration. However, in our data sample we observe only the amount of self-study and course attendance times allocated to the first academic year;

- we do not observe the grades for first year exams not attempted during the first year;

- we do not observe the grades for exams attempted but not passed (i.e. grade $<18)$;

- grades higher than 31 (i.e. 30/30 cum laude) are recorded as 31.

In order to estimate the exam performance regressions we used a censored regression model, namely the cnreg command in STATA ${ }^{21}$. In particular, for the observations with missing grades we imputed an observed grade $G_{i}^{o}$ equal to 17.999 (since the minimum passing grade is 18) and set the variable indicating censoring at -1 , i.e. left censoring: the true or latent grade $G_{i}^{*}$ is known only to be less or equal to 17.999. For the observations with grades equal to 31 we set the variable indicating censoring at 1, i.e. right censoring: the true grade is known only to be greater or equal to the value recorded (i.e. 31). The log likelihood for the single exam performance model is:

production function as a part of a broader utility maximization problem is already present in McGuckin and Winker (1979).

${ }^{20} \mathrm{e} . \mathrm{g}$. the value of the LR-test for model M2 in table 9 is $\chi^{2}(47)=46.16$, p-value $=0.51$.

${ }^{21}$ See the tobit command in the STATA 7 reference manual (STATA 2001). 


$$
\begin{aligned}
L= & -\frac{1}{2} \sum_{j \in C}\left\{\left(\frac{G_{i}^{o}-x \beta}{\sigma}\right)^{2}+\ln \left(2 \pi \sigma^{2}\right)\right\} \\
& +\sum_{j \in L} \ln \left\{\Phi\left(\frac{G_{i}^{o}-x \beta}{\sigma}\right)\right\} \\
& +\sum_{j \in R} \ln \left\{1-\Phi\left(\frac{G_{i}^{o}-x \beta}{\sigma}\right)\right\}
\end{aligned}
$$

where $j \in C$ are the uncensored observations, $j \in L$ are the left censored observations and $j \in R$ the right censored observations, $\Phi($.$) is the standard$ normal distribution function, $x$ are the covariates included in the exam performance regressions, $\beta$ are the coefficients to be estimated and $\sigma$ is the error term $(\ln (e))$ standard deviation.

Included as explanatory variables in the structural form of the educational performance function were the type of secondary school and the secondary school final exam score interacted with the type of secondary school, ${ }^{22}$ as proxies for ability and the type and amount of previous knowledge, and lecture attendance and self-study time. We considered four types of secondary school: classical or scientific liceo, ${ }^{23}$ technical school, accounting school, other secondary schools ${ }^{24}$.

The results of the single exam estimates are shown in tables 4-8.

The tables show the results for two type of models. Model 1 (M1) includes pre-university school characteristics and time of lecture attendance, while model 2 (M2) also includes time devoted to self-study. Here, we comment on the performance elasticities with respect to attendance and self-study time only. For all exams we find that including the time of lecture attendance only produces an overestimation of the elasticity of course attendance compared to the complete specification (model 2). In most exams, ${ }^{25}$ the size of the overestimation is surprisingly very close to the elasticity estimated for self-study time in model 2, as predicted by our simple theoretical model. This implies that educational performance regressions omitting time devoted to self-study may produce substantially biased estimates of the elasticity of performance with respect to lecture attendance and wrong policy implications.

\footnotetext{
${ }^{22}$ We do not address here the issue of the potential endogeneity of previous school results. This problem is treated for instance in Dolton et al. (2001), who disregard, however, the potential endogeneity of student time allocation.

${ }^{23}$ Liceo is a academic high school usually chosen by individuals who plan to undertake a university education.

${ }^{24}$ Such as vocational secondary schools.

${ }^{25}$ The sole exception is Law.
} 
Table 4: Performance equation for Law (Censored regression)

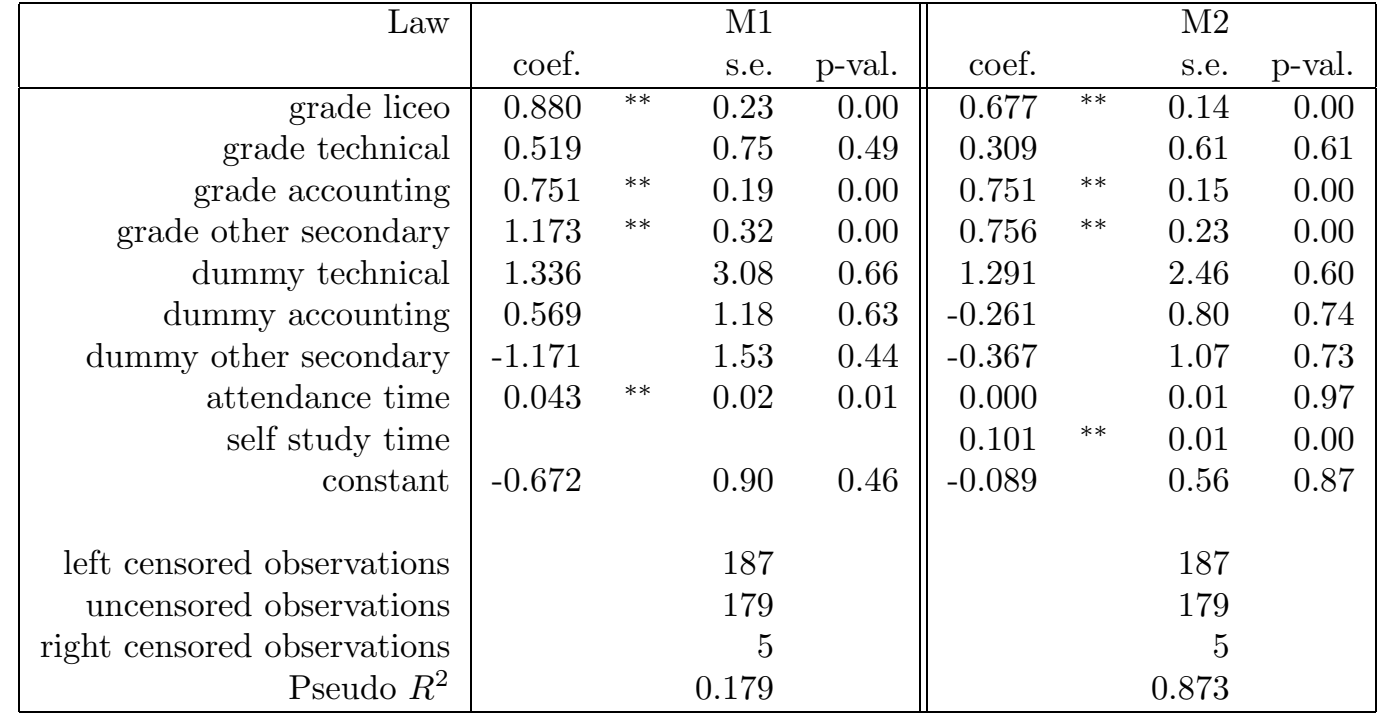

Note. Standard errors (s.e.) are computed with bootstrap (500 replications). The reference group are students from liceo.

* significant at the $10 \%$ statistical level ${ }^{* *}$ significant at the $5 \%$ statistical level.

Table 5: Performance equation for Mathematics (Censored regression)

\begin{tabular}{|c|c|c|c|c|c|c|c|c|}
\hline \multirow{2}{*}{ Mathematics } & \multicolumn{4}{|c|}{ M1 } & \multicolumn{4}{|c|}{ M2 } \\
\hline & coef. & & s.e. & p-val. & coef. & & s.e. & p-val. \\
\hline grade liceo & 0.689 & $* *$ & 0.11 & 0.00 & 0.597 & $* *$ & 0.11 & 0.00 \\
\hline grade technical & 0.878 & & 0.71 & 0.22 & 0.892 & & 0.80 & 0.26 \\
\hline grade accounting & 1.138 & $* *$ & 0.24 & 0.00 & 0.906 & $* *$ & 0.19 & 0.00 \\
\hline grade other secondary & 0.691 & & 0.43 & 0.11 & 0.659 & * & 0.38 & 0.08 \\
\hline dummy technical & -1.059 & & 2.65 & 0.69 & -1.429 & & 3.01 & 0.63 \\
\hline dummy accounting & -2.058 & $* *$ & 1.03 & 0.05 & -1.426 & & 0.88 & 0.11 \\
\hline dummy other secondary & -0.223 & & 1.72 & 0.90 & -0.428 & & 1.51 & 0.78 \\
\hline attendance time & 0.148 & $* *$ & 0.03 & 0.00 & 0.065 & * & 0.03 & 0.06 \\
\hline self study time & & & & & 0.077 & $* *$ & 0.01 & 0.00 \\
\hline constant & -0.179 & & 0.48 & 0.71 & 0.184 & & 0.47 & 0.70 \\
\hline left censored observations & & & 182 & & & & 182 & \\
\hline uncensored observations & & & 189 & & & & 189 & \\
\hline right censored observations & & & 0 & & & & 0 & \\
\hline Pseudo $R^{2}$ & & & 0.486 & & & & 0.819 & \\
\hline
\end{tabular}

Note. Standard errors (s.e.) are computed with bootstrap (500 replications). The reference group are students from liceo.

* significant at the $10 \%$ statistical level ** significant at the $5 \%$ statistical level. 
Table 6: Performance equation for Accounting (Censored regression)

\begin{tabular}{|c|c|c|c|c|c|c|c|c|}
\hline \multirow[t]{2}{*}{ Accounting } & \multicolumn{4}{|c|}{ M1 } & \multicolumn{4}{|c|}{ M2 } \\
\hline & coef. & & s.e. & p-val. & coef. & & s.e. & p-val. \\
\hline grade liceo & 0.369 & $* *$ & 0.15 & 0.01 & 0.492 & ** & 0.11 & 0.00 \\
\hline grade technical & 1.037 & & 1.05 & 0.32 & 1.264 & & 1.23 & 0.30 \\
\hline grade accounting & 0.733 & $* *$ & 0.16 & 0.00 & 0.540 & $* *$ & 0.13 & 0.00 \\
\hline grade other secondary & 1.068 & $* *$ & 0.26 & 0.00 & 0.753 & $* *$ & 0.20 & 0.00 \\
\hline dummy technical & -2.702 & & 4.04 & 0.50 & -3.036 & & 4.67 & 0.52 \\
\hline dummy accounting & -1.292 & & 0.86 & 0.13 & -0.115 & & 0.68 & 0.87 \\
\hline dummy other secondary & -2.665 & $* *$ & 1.19 & 0.03 & -1.007 & & 0.90 & 0.26 \\
\hline attendance time & 0.165 & $* *$ & 0.02 & 0.00 & 0.031 & $* *$ & 0.02 & 0.05 \\
\hline self study time & & & & & 0.100 & $* *$ & 0.01 & 0.00 \\
\hline constant & 0.928 & & 0.58 & 0.11 & 0.615 & & 0.42 & 0.15 \\
\hline left censored observations & & & 145 & & & & 145 & \\
\hline uncensored observations & & & 224 & & & & 224 & \\
\hline right censored observations & & & 2 & & & & 2 & \\
\hline Pseudo $R^{2}$ & & & 0.422 & & & & 1.000 & \\
\hline
\end{tabular}

Note. Standard errors (s.e.) are computed with bootstrap (500 replications). The reference group are students from liceo.

* significant at the $10 \%$ statistical level ${ }^{* *}$ significant at the $5 \%$ statistical level.

Table 7: Performance equation for Economics (Censored regression)

\begin{tabular}{|c|c|c|c|c|c|c|c|c|}
\hline \multirow[t]{2}{*}{ Economics } & \multicolumn{4}{|c|}{ M1 } & \multicolumn{4}{|c|}{ M2 } \\
\hline & coef. & & s.e. & p-val. & coef. & & s.e. & p-val. \\
\hline grade liceo & 0.942 & ** & 0.20 & 0.00 & 0.583 & ** & 0.15 & 0.00 \\
\hline grade technical & 1.277 & & 1.46 & 0.38 & 0.531 & & 0.55 & 0.33 \\
\hline grade accounting & 1.062 & ** & 0.22 & 0.00 & 0.801 & ** & 0.17 & 0.00 \\
\hline grade other secondary & 1.592 & ** & 0.52 & 0.00 & 1.386 & ** & 0.39 & 0.00 \\
\hline dummy technical & -1.520 & & 5.50 & 0.78 & 0.132 & & 2.12 & 0.95 \\
\hline dummy accounting & -0.544 & & 1.16 & 0.64 & -0.923 & & 0.90 & 0.31 \\
\hline dummy other secondary & -2.712 & & 2.24 & 0.23 & -3.278 & * & 1.69 & 0.05 \\
\hline attendance time & 0.203 & ** & 0.06 & 0.00 & 0.084 & * & 0.05 & 0.07 \\
\hline self study time & & & & & 0.097 & ** & 0.01 & 0.00 \\
\hline constant & -1.462 & * & 0.75 & 0.05 & 0.080 & & 0.58 & 0.89 \\
\hline left censored observations & & & 188 & & & & 188 & \\
\hline uncensored observations & & & 172 & & & & 172 & \\
\hline right censored observations & & & 11 & & & & 11 & \\
\hline Pseudo $R^{2}$ & & & 0.297 & & & & 0.750 & \\
\hline
\end{tabular}

Note. Standard errors (s.e.) are computed with bootstrap (500 replications). The reference group are students from liceo.

${ }^{*}$ significant at the $10 \%$ statistical level ${ }^{* *}$ significant at the $5 \%$ statistical level. 
Table 8: Performance equation for Economic History (Censored regression)

\begin{tabular}{|c|c|c|c|c|c|c|c|c|}
\hline \multirow[t]{2}{*}{ Economic History } & \multicolumn{4}{|c|}{ M1 } & \multicolumn{4}{|c|}{ M2 } \\
\hline & coef. & & s.e. & p-val. & coef. & & s.e. & p-val. \\
\hline grade liceo & 0.156 & & 0.22 & 0.47 & 0.142 & & 0.12 & 0.24 \\
\hline grade technical & 1.525 & & 1.09 & 0.16 & 0.528 & & 0.85 & 0.54 \\
\hline grade accounting & 0.614 & $* *$ & 0.28 & 0.03 & 0.262 & & 0.18 & 0.15 \\
\hline grade other secondary & 1.054 & * & 0.58 & 0.07 & 0.609 & $*$ & 0.37 & 0.10 \\
\hline dummy technical & -5.427 & & 4.32 & 0.21 & -1.541 & & 3.33 & 0.64 \\
\hline dummy accounting & -1.948 & & 1.39 & 0.16 & -0.533 & & 0.86 & 0.54 \\
\hline dummy other secondary & -3.615 & & 2.43 & 0.14 & -1.886 & & 1.47 & 0.20 \\
\hline attendance time & 0.115 & $* *$ & 0.02 & 0.00 & 0.030 & $* *$ & 0.01 & 0.02 \\
\hline self study time & & & & & 0.123 & $* *$ & 0.01 & 0.00 \\
\hline constant & 2.037 & $* *$ & 0.83 & 0.02 & 2.015 & $* *$ & 0.46 & 0.00 \\
\hline left censored observations & & & 206 & & & & 206 & \\
\hline uncensored observations & & & 164 & & & & 164 & \\
\hline right censored observations & & & 1 & & & & 1 & \\
\hline Pseudo $R^{2}$ & & & 0.141 & & & & 0.970 & \\
\hline
\end{tabular}

Note. Standard errors (s.e.) are computed with bootstrap (500 replications). The reference group are students from liceo.

* significant at the $10 \%$ statistical level ** significant at the $5 \%$ statistical level.

In all exams we find that the elasticity of performance with respect to time of attendance is lower than that with respect to self-study. Quantitative and qualitative results differ across exams. In Law, only the time devoted to self-study seems to affect the grade obtained. Increasing hours of self-study by $1 \%$ raises the grade by $0.10 \%$. In Mathematics both course attendance and self-study time are important for the exam performance, increasing the former by $1 \%$ increases the grade by $0.065 \%$ while raising the hours of study by $1 \%$ raises the grade by $0.077 \%$. For Accounting the level of the performance elasticity of attendance is much lower than that of self-study, 0.031 and 0.10 , respectively. In Economics both attendance and self-study have a positive effect upon performance with elasticities of 0.084 and 0.097 , respectively. Last but not least, attendance and self-study both have a statistically significant positive effect on performance in economic history, with elasticities of 0.03 and 0.123 , respectively.

In brief, we find that there are marked differences in the benefits produced by lecture attendance and self-study in terms of grades earned across exams. There are exams, such as Law, in which only self-study seems to have a positive effect in terms of performance, exams, such as Accounting and Economic History, in which self-study is more effective in terms of higher performance and finally exams, such as Economics and Mathematics, in which the gains 
Table 9: Overall performance equation (IV)

\begin{tabular}{|c|c|c|c|c|c|c|c|c|}
\hline \multirow[t]{2}{*}{ Overall performance } & \multicolumn{4}{|c|}{ M1 } & \multicolumn{4}{|c|}{ M2 } \\
\hline & coef. & & s.e. & p-val. & coef. & & s.e. & p-val. \\
\hline grade liceo & 2.919 & $* *$ & 0.39 & 0.00 & 2.236 & ** & 0.19 & 0.00 \\
\hline grade technical & 5.722 & $* *$ & 1.98 & 0.00 & 3.633 & ** & 0.54 & 0.00 \\
\hline grade accounting & 4.547 & $* *$ & 0.41 & 0.00 & 3.489 & ** & 0.20 & 0.00 \\
\hline grade other secondary & 5.528 & $* *$ & 0.57 & 0.00 & 4.033 & ** & 0.33 & 0.00 \\
\hline dummy technical & -11.661 & & 7.68 & 0.13 & -5.997 & ** & 2.19 & 0.01 \\
\hline dummy accounting & -6.642 & $* *$ & 2.19 & 0.00 & -5.138 & ** & 1.14 & 0.00 \\
\hline dummy other secondary & -10.571 & $* *$ & 2.62 & 0.00 & -7.420 & $* *$ & 1.49 & 0.00 \\
\hline attendance Law & 0.032 & & 0.06 & 0.58 & 0.029 & & 0.03 & 0.30 \\
\hline attendance Mathematics & 0.143 & $* *$ & 0.06 & 0.02 & 0.060 & * & 0.03 & 0.05 \\
\hline attendance Accounting & 0.156 & $* *$ & 0.07 & 0.02 & 0.078 & $* *$ & 0.04 & 0.03 \\
\hline attendance Economics & 0.289 & $* *$ & 0.07 & 0.00 & 0.100 & $* *$ & 0.04 & 0.00 \\
\hline attendance Ec. History & 0.038 & & 0.05 & 0.46 & 0.021 & & 0.02 & 0.37 \\
\hline self study Law & & & & & 0.094 & ** & 0.01 & 0.00 \\
\hline self study Mathematics & & & & & 0.059 & ** & 0.01 & 0.00 \\
\hline self study Accounting & & & & & 0.081 & ** & 0.01 & 0.00 \\
\hline self study Economics & & & & & 0.118 & ** & 0.01 & 0.00 \\
\hline self study Ec. History & & & & & 0.112 & ** & 0.01 & 0.00 \\
\hline constant & 1.173 & & 1.49 & 0.45 & 3.793 & ** & 0.75 & 0.00 \\
\hline n. observations & & & 371 & & & & 371 & \\
\hline $\operatorname{adj} R^{2}$ & & & 0.656 & & & & 0.911 & \\
\hline
\end{tabular}

Note. Standard errors (s.e.) are computed with bootstrap (500 replications). The reference group are students from liceo. ${ }^{*}$ significant at the $10 \%$ statistical level ${ }^{* *}$ significant at the $5 \%$ statistical level. 
of performance obtained by increasing attendance and self-study are very similar in magnitude. In general, therefore, performance gains related to increasing attendance are higher in quantitative disciplines.

As we have seen, an alternative approach to estimating the elasticities of performance with respect to attendance and self-study time for the individual exams would be to estimate the overall performance regression (6) directly obtained from our analytical model. However, before estimating equation (6) we had to fill the missing observations related to the exams not passed (or not attempted). This was necessary because we were not able to take account of the censoring of the observations for the overall performance, since individuals may have attempted and passed a very different number of exams. Hence, we imputed the predicted exam performance obtained from the single exam regressions to individuals for which the mark in some exams was not observed. The results are shown in table 9 . We obtained qualitatively equivalent results and slightly different elasticities with respect to the single performance regressions. ${ }^{26}$ We interpret this as evidence that our analytical model, though simple, fits the data remarkably well.

\section{Conclusions}

In this paper we have introduced a theoretical model of student time allocation and academic performance. The model accounts for the endogeneity of both course attendance and self-study and the fact that a student when a student decides the optimal values of these choice variables $\mathrm{s} /$ he is subject to a common time constraint. We obtain from the model some testable implications. In particular that regressions omitting self-study time overestimate the elasticity of exam performance with respect to lecture attendance and that the size of the overestimation is exactly the elasticity of performance with respect to self-study. We then have estimated an empirical model of student performance using data on first year economics students at the University of Ancona (Italy). Both theoretical implications were confirmed by the empirical analysis. Moreover, we found that the relative importance of self-study time and attendance varies across exams. Attendance appears to produce performance gains especially in quantitative disciplines such as Mathematics and Economics, while self-study time is central for performance in non-quantitative disciplines such as Law and Economic History. A major implication of our analysis is that estimates of educational performance

\footnotetext{
${ }^{26}$ This might be due to the cross-correlations between attendance and self-study in different exams and that in the overall performance regression we are working for some individuals with latent (imputed) performance.
} 
functions excluding self-study time are likely to produce an over-evaluation of the elasticity of performance with respect to lecture attendance and to generate wrong policy directions.

\section{References}

[1] Allison, E. (1982), "Educational Production Functions for an Introductory Economics Course", in Rendigs Fels and John J. Siegfried, eds., Research on Teaching College Economics, New York: Joint Council Economic Education.

[2] Bratti, M. and Staffolani, S. (2001) 'Performance Accademica e Scelta della Facoltà Universitaria: Aspetti Teorici e Evidenza Empirica', Rivista di Politica Economica, 91(7-8), 203-244.

[3] Chan, K. C., Shum, C. and Wright, D. J. (1997) 'Class Attendance and Student Performance in Principles of Finance', Financial Practice and Education, 7(2), 58-65.

[4] Chizmar, J. F. and Zak, T. A. (1983) 'Modeling Multiple Outputs in Educational Production Functions', American Economic Review, 73(2), $18-22$.

[5] Chizmar, J. F. and Zak, T. A. (1984) 'Canonical Estimation of Joint Educational Production Functions', Economics of Education Review, 3(1), $37-43$.

[6] Devadoss, S. and Foltz, J. (1996) 'Evaluation of Factors Influencing Student Class Attendance and Performance', American Journal of Agricultural Economics, 78(3), 499-507.

[7] Dolton, P., Marcenaro, O. D. and Navarro, L.(2001) 'The Effective Use of Student Time: A Stochastic Frontier Production Function Case Study', Center for the Economics of Education, London School of Economics, London.

[8] Durden, G. C. and Ellis, L. V. (1995) 'The Effects of Attendance on Student Learning in Principles of Economics', American Economic Review, 85(2), 343-346.

[9] Gambetta, D. (1987) Were They Pushed or Did They Jump?, Cambridge: Cambridge University Press. 
[10] HEFCE (1999) Performance Indicators in Higher Education. First Report of the Performance Indicators Steering Group (PISG). Bristol: HEFCE.

[11] Lazear, E. P. (2001) 'Educational Production', Quarterly Journal of Economics, 116(3), 777-803.

[12] McGuckin, R. H. and Winkler, D. R. (1979) 'University Resources in the Production of Education', Review of Economics and Statistics, 61(2), 241-248.

[13] Monk, D. H. (1990) Educational Finance: An Economic Approach, New York: McGraw-Hill.

[14] Pritchett, L. and Filmer, D. (1999), 'What Education Production Functions Really Show: A Positive Theory of Education and Expenditures", Economics of Education Review, 18(2), 223-239.

[15] Romer, D. (1993) 'Do Students Go to Class? Should They?', Journal of Economic Perspectives, 7(3), 167-174.

[16] Schimdt, R. M. (1983) 'Who Maximizes What? A Study in Student Time Allocation', American Economic Review, 73(2), 23-28.

[17] Shavit, Y. and Blossfeld, H. P.(1993) Persistent Inequality, Westview Press, Boulder.

[18] STATA (2001) STATA 7 Reference Manual, volume 4, Stata Press, College Station, Texas.

[19] Stewart, M. (1983) 'On Least Squares Estimation When the Dependent Variable Is Grouped', Review of Economic Studies, 50(4), 737-53. 


\section{Appendix}

Table A1: Variables legend

\begin{tabular}{ll}
\hline Name & Description \\
\hline mot1 & Motivation for faculty choice: unknown \\
mot2 & Motivation for faculty choice: distance \\
mot3 & Motivation for faculty choice: professional project (reference) \\
mot4 & Motivation for faculty choice: employment prospects \\
mot5 & Motivation for faculty choice: cultural reasons \\
mot6 & Motivation for faculty choice: social status \\
mot7 & Motivation for faculty choice: advice of parents or friends \\
mot8 & Motivation for faculty choice: to improve employment prospects \\
eduf1 & Father's education: elementary school or lower (reference) \\
eduf2 & Father's education: low secondary school \\
eduf3 & Father's education: high secondary school \\
eduf4 & Father's education: university degree \\
eduf5 & Father's education: unknown \\
edum1 & Mother's education: elementary school or lower (reference) \\
edum2 & Mother's education: low secondary school \\
edum3 & Mother's education: high secondary school \\
edum4 & Mother's education: university degree \\
edum5 & Mother's education: unknown \\
scf1 & Father's social class: professional \\
scf2 & Father's social class: intermediate \\
scf3 & Father's social class: skilled non manual \\
scf4 & Father's social class: skilled manual \\
scf5 & Father's social class: unskilled \\
scf6 & Father's social class: other \\
scf7 & Father's social class: unknown \\
scf8 & Father's social class: non worker (reference) \\
scm1 & Mother's social class: professional \\
scm2 & Mother's social class: intermediate \\
\hline
\end{tabular}


continue table A1. Variables legend

\begin{tabular}{|c|c|}
\hline Name & Description \\
\hline scm3 & Mother's social class: skilled non manual \\
\hline $\operatorname{scm} 4$ & Mother's social class: skilled manual \\
\hline $\operatorname{scm} 5$ & Mother's social class: unskilled \\
\hline scm6 & Mother's social class: other \\
\hline scm7 & Mother's social class: unknown \\
\hline scm8 & Mother's social class: non worker (reference) \\
\hline yfa1 & Monthly father's income: unknown \\
\hline yfa2 & Monthly father's income: no income \\
\hline yfa3 & Monthly father's income: $<516 €$ (reference) \\
\hline yfa4 & Monthly father's income: $516-774 €$ \\
\hline yfa5 & Monthly father's income: $774-1032 €$ \\
\hline yfa6 & Monthly father's income: $1032-1549 €$ \\
\hline yfa7 & Monthly father's income: $1549-2065 €$ \\
\hline yfa 8 & Monthly father's income: $2065-3098 €$ \\
\hline ymo1 & Monthly mother's income: unknown \\
\hline ymo2 & Monthly mother's income: no income \\
\hline ymo3 & Monthly mother's income: $<516 €$ (reference) \\
\hline ymo4 & Monthly mother's income: $516-774 €$ \\
\hline ymo5 & Monthly mother's income: 774-1032 € \\
\hline ymo6 & Monthly mother's income: $1032-1549 €$ \\
\hline ymo7 & Monthly mother's income: $2065-3098 €$ \\
\hline male & Male (reference) \\
\hline female & Female \\
\hline grade1 & Grade in final secondary school exam: liceo \\
\hline grade2 & Grade in final secondary school exam: technical school \\
\hline grade3 & Grade in final secondary school exam: accounting school \\
\hline grade4 & Grade in final secondary school exam: other secondary school \\
\hline dummy d1 & Dummy for liceo (reference) \\
\hline dummy d2 & Dummy for technical school \\
\hline dummy d3 & Dummy for accounting school \\
\hline dummy d4 & Dummy for other secondary school \\
\hline dom1 & Residence during the first year: unknown \\
\hline $\operatorname{dom} 2$ & Residence during the first year: outside Ancona \\
\hline dom3 & Residence during the first year: partly in Ancona \\
\hline $\operatorname{dom} 4$ & Residence during the first year: Ancona (reference) \\
\hline age & Age at enrollment \\
\hline
\end{tabular}


Table A2: Interval regression estimates for hours of lecture attendance

\begin{tabular}{|c|c|c|c|c|c|c|c|c|c|c|}
\hline \multirow[t]{2}{*}{ Variable } & \multicolumn{2}{|c|}{ Law } & \multicolumn{2}{|c|}{ Mathematics } & $\begin{array}{r}\text { Cou } \\
\text { Accou }\end{array}$ & $\begin{array}{l}\text { rse } \\
\text { hting }\end{array}$ & \multicolumn{2}{|c|}{ Economics } & \multicolumn{2}{|c|}{ Ec. History } \\
\hline & coef. & t-val & coef. & t-val & coef. & t-val & coef. & $\mathrm{t}$-val & coef. & t-val \\
\hline mot1 & -10.98 & -1.20 & -12.25 & -1.70 & -1.05 & -0.12 & -4.54 & -0.55 & -6.16 & -0.69 \\
\hline $\operatorname{mot} 2$ & 9.44 & 1.38 & 9.28 & 1.72 & 17.61 & 2.75 & 7.61 & 1.23 & 6.10 & 0.91 \\
\hline $\operatorname{mot} 4$ & -4.90 & -1.27 & 1.42 & 0.46 & 2.24 & 0.61 & 2.62 & 0.74 & -2.51 & -0.66 \\
\hline $\operatorname{mot} 5$ & 0.53 & 0.07 & -2.61 & -0.42 & -15.47 & -2.11 & -18.84 & -2.65 & -8.92 & -1.17 \\
\hline mot6 & -22.17 & -0.69 & -10.79 & -0.42 & -1.33 & -0.04 & 15.47 & 0.53 & 6.82 & 0.22 \\
\hline $\operatorname{mot} 7$ & -14.23 & -1.04 & -1.13 & -0.10 & -5.68 & -0.44 & -17.40 & -1.40 & 6.02 & 0.45 \\
\hline $\operatorname{mot} 8$ & -24.03 & -1.42 & -7.33 & -0.55 & 2.94 & 0.19 & 5.52 & 0.36 & -10.91 & -0.66 \\
\hline eduf2 & 5.64 & 1.03 & -1.39 & -0.32 & 2.19 & 0.42 & -2.36 & -0.47 & 2.87 & 0.53 \\
\hline eduf3 & -0.33 & -0.05 & -5.47 & -1.08 & -2.63 & -0.44 & -5.73 & -0.98 & 2.18 & 0.34 \\
\hline eduf4 & 0.03 & 0.00 & -3.37 & -0.53 & -5.70 & -0.75 & -1.93 & -0.26 & -8.79 & -1.11 \\
\hline eduf5 & 22.34 & 1.52 & -1.46 & -0.13 & 28.08 & 2.04 & 14.02 & 1.05 & 10.02 & 0.69 \\
\hline edum2 & -4.95 & -0.88 & -1.11 & -0.25 & -1.73 & -0.33 & 6.96 & 1.37 & -3.86 & -0.70 \\
\hline edum3 & -6.95 & -1.05 & -5.14 & -0.98 & 0.23 & 0.04 & 10.25 & 1.70 & -4.13 & -0.64 \\
\hline edum4 & -6.55 & -0.73 & -5.53 & -0.78 & 1.82 & 0.22 & 16.61 & 2.04 & 2.76 & 0.31 \\
\hline edum5 & -9.31 & -0.70 & -16.35 & -1.55 & -25.73 & -2.06 & -13.25 & -1.09 & -2.68 & -0.20 \\
\hline scf1 & 9.54 & 1.06 & 7.93 & 1.11 & 12.97 & 1.53 & 8.85 & 1.08 & -7.48 & -0.84 \\
\hline scf2 & 4.08 & 0.44 & 2.54 & 0.35 & 6.78 & 0.78 & 4.72 & 0.56 & 6.89 & 0.76 \\
\hline scf3 & 15.33 & 1.71 & 10.61 & 1.50 & 8.53 & 1.01 & 9.50 & 1.17 & 2.68 & 0.31 \\
\hline scf4 & 1.09 & 0.13 & -1.53 & -0.23 & -0.31 & -0.04 & -2.78 & -0.36 & -9.03 & -1.08 \\
\hline scf5 & -33.10 & -1.34 & 13.68 & 0.70 & -21.79 & -0.95 & -19.73 & -0.89 & -38.53 & -1.60 \\
\hline scf6 & 7.45 & 0.59 & 13.81 & 1.39 & -1.07 & -0.09 & 14.08 & 1.23 & -5.92 & -0.48 \\
\hline scf7 & -3.23 & -0.27 & -1.03 & -0.11 & 15.56 & 1.40 & 1.65 & 0.15 & -3.38 & -0.29 \\
\hline scm1 & -15.71 & -1.47 & -8.47 & -1.00 & 7.62 & 0.76 & 2.89 & 0.30 & 27.92 & 2.66 \\
\hline scm2 & 1.29 & 0.18 & 5.66 & 1.01 & 2.08 & 0.31 & -2.28 & -0.35 & 2.48 & 0.35 \\
\hline scm3 & -13.95 & -1.97 & -12.93 & -2.31 & -7.47 & -1.12 & -10.46 & -1.62 & 4.62 & 0.66 \\
\hline scm4 & 5.38 & 0.87 & 4.70 & 0.96 & 9.41 & 1.61 & 8.34 & 1.48 & 13.73 & 2.26 \\
\hline scm5 & -3.24 & -0.29 & -4.77 & -0.53 & 13.38 & 1.25 & 5.52 & 0.53 & 33.56 & 3.00 \\
\hline scm6 & -5.67 & -0.51 & -12.45 & -1.41 & -1.71 & -0.16 & -11.64 & -1.15 & 6.80 & 0.62 \\
\hline scm7 & 3.15 & 0.39 & 2.60 & 0.40 & -3.89 & -0.51 & -6.17 & -0.84 & 10.97 & 1.38 \\
\hline yfa1 & -2.77 & -0.33 & -7.93 & -1.21 & -14.73 & -1.89 & -9.72 & -1.29 & -8.88 & -1.09 \\
\hline yfa2 & 2.45 & 0.15 & -18.88 & -1.49 & -3.06 & -0.20 & -1.24 & -0.08 & -4.36 & -0.28 \\
\hline yfa4 & -4.26 & -0.51 & -7.86 & -1.19 & -11.63 & -1.48 & -3.35 & -0.44 & -4.66 & -0.57 \\
\hline yfa5 & 0.70 & 0.09 & -6.95 & -1.08 & -7.89 & -1.04 & -11.43 & -1.55 & -10.53 & -1.32 \\
\hline yfa6 & -1.22 & -0.14 & -15.97 & -2.27 & -12.63 & -1.51 & -13.96 & -1.73 & -11.29 & -1.30 \\
\hline yfa7 & -0.45 & -0.05 & -10.04 & -1.32 & -11.40 & -1.27 & -12.36 & -1.42 & -14.64 & -1.56 \\
\hline yfa8 & -13.70 & -1.30 & -21.63 & -2.59 & -35.95 & -3.63 & -28.69 & -2.99 & -12.44 & -1.20 \\
\hline
\end{tabular}


continue table A2. Interval regression estimates for hours of lecture attendance

\begin{tabular}{|c|c|c|c|c|c|c|c|c|c|c|}
\hline \multirow{3}{*}{ Variable } & \multicolumn{10}{|c|}{ Course } \\
\hline & \multicolumn{2}{|c|}{ Law } & \multicolumn{2}{|c|}{ Mathematics } & \multicolumn{2}{|c|}{ Accounting } & \multicolumn{2}{|c|}{ Economics } & \multicolumn{2}{|c|}{ Ec. History } \\
\hline & coef. & t-val & coef. & t-val & coef. & t-val & coef. & t-val & coef. & t-val \\
\hline ymo1 & 11.31 & 1.53 & 4.20 & 0.72 & 1.83 & 0.26 & 2.55 & 0.38 & 12.78 & 1.76 \\
\hline ymo2 & 6.01 & 0.79 & -2.82 & -0.47 & 0.43 & 0.06 & -0.51 & -0.07 & 2.16 & 0.29 \\
\hline ymo4 & 5.01 & 0.69 & -4.37 & -0.75 & -10.50 & -1.53 & -9.31 & -1.40 & -6.11 & -0.85 \\
\hline ymo5 & 6.88 & 0.95 & -4.08 & -0.71 & -7.02 & -1.03 & -4.43 & -0.67 & 2.51 & 0.35 \\
\hline ymo6 & 6.53 & 0.63 & 9.74 & 1.19 & -3.28 & -0.34 & -14.22 & -1.51 & 6.02 & 0.59 \\
\hline ymo7 & 9.77 & 0.86 & 10.13 & 1.13 & -7.17 & -0.67 & -8.70 & -0.84 & 2.31 & 0.21 \\
\hline female & -0.69 & -0.19 & -2.38 & -0.81 & 3.14 & 0.90 & -3.83 & -1.13 & -2.78 & -0.76 \\
\hline grade1 & -42.92 & -1.55 & -35.43 & -1.62 & 34.90 & 1.34 & 34.96 & 1.38 & 5.17 & 0.19 \\
\hline grade2 & -84.88 & -2.14 & -4.94 & -0.16 & 28.23 & 0.76 & 29.00 & 0.80 & -1.11 & -0.03 \\
\hline grade3 & -166.17 & -2.58 & -168.16 & -3.30 & -59.63 & -0.99 & -68.71 & -1.17 & 63.95 & 1.01 \\
\hline grade 4 & -0.47 & -1.22 & -0.09 & -0.31 & 0.38 & 1.06 & 0.63 & 1.82 & 0.90 & 2.40 \\
\hline dummy d2 & 2.82 & 2.11 & 3.03 & 2.86 & 1.54 & 1.22 & 1.76 & 1.44 & -0.57 & -0.43 \\
\hline dummy d3 & 0.43 & 1.04 & 0.48 & 1.45 & -0.45 & -1.15 & -0.26 & -0.69 & 0.59 & 1.45 \\
\hline dummy d4 & 1.21 & 1.66 & -0.26 & -0.44 & -0.39 & -0.57 & -0.19 & -0.29 & 0.91 & 1.27 \\
\hline $\operatorname{dom} 1$ & -7.29 & -0.78 & -23.65 & -3.19 & -12.52 & -1.42 & -13.17 & -1.54 & -6.59 & -0.72 \\
\hline dom2 & -2.77 & -0.71 & -0.88 & -0.28 & -4.20 & -1.14 & -5.58 & -1.57 & -7.41 & -1.93 \\
\hline dom3 & -3.71 & -0.71 & 2.26 & 0.54 & -1.95 & -0.39 & -4.70 & -0.98 & 0.74 & 0.14 \\
\hline age & -5.96 & -3.89 & -8.57 & -7.16 & -6.47 & -4.51 & -7.02 & -5.05 & -2.48 & -1.65 \\
\hline constant & 192.39 & 5.12 & 260.85 & 8.83 & 185.00 & 5.24 & 189.64 & 5.55 & 55.68 & 1.51 \\
\hline N. obs. & 371 & & 371 & & 371 & & 371 & & 371 & \\
\hline LR-test* & 0.12 & & 0.00 & & 0.00 & & 0.00 & & 0.08 & \\
\hline
\end{tabular}

Note. ${ }^{*}$ p-values. The dependent variables is the number of hours of lecture attendance. For the description of the explanatory variables see table A1. 
Table A3: Interval regression estimates for hours of self-study

\begin{tabular}{|c|c|c|c|c|c|c|c|c|c|c|}
\hline \multirow[t]{2}{*}{ Variable } & \multicolumn{10}{|c|}{ Course } \\
\hline & coef. & $\mathrm{t}$-val & coef. & t-val & coef. & $\mathrm{t}$-val & coef. & $\mathrm{t}$-val & coef. & t-val \\
\hline mot1 & 111.83 & 2.52 & -26.28 & -0.73 & -25.54 & -0.74 & 38.86 & 0.99 & 27.74 & 0.98 \\
\hline $\operatorname{mot} 2$ & 67.71 & 2.31 & 55.17 & 2.03 & 26.94 & 1.05 & 7.35 & 0.25 & -10.22 & -0.49 \\
\hline $\operatorname{mot} 4$ & 39.85 & 2.49 & -4.07 & -0.27 & -16.12 & -1.10 & 21.89 & 1.32 & -20.67 & -1.74 \\
\hline $\operatorname{mot} 5$ & -4.42 & -0.12 & -28.61 & -0.93 & -74.54 & -2.55 & -41.16 & -1.23 & 4.50 & 0.19 \\
\hline $\operatorname{mot} 6$ & 632.78 & 0.04 & -103.73 & -0.83 & 7.34 & 0.06 & 99.78 & 0.72 & 73.51 & 0.73 \\
\hline $\operatorname{mot} 7$ & -40.81 & -0.60 & -53.72 & -0.99 & -53.11 & -1.03 & -66.49 & -1.14 & -53.42 & -1.28 \\
\hline $\operatorname{mot} 8$ & -29.16 & -0.42 & -37.97 & -0.57 & -43.59 & -0.69 & -55.63 & -0.76 & -23.03 & -0.45 \\
\hline eduf2 & 8.85 & 0.38 & -5.93 & -0.27 & -19.91 & -0.96 & -33.92 & -1.44 & 8.81 & 0.53 \\
\hline eduf3 & 38.66 & 1.37 & 12.90 & 0.51 & -21.33 & -0.88 & -30.79 & -1.11 & 3.83 & 0.19 \\
\hline eduf4 & 10.36 & 0.29 & 54.66 & 1.70 & -18.48 & -0.60 & 1.52 & 0.04 & 14.95 & 0.60 \\
\hline eduf5 & 82.28 & 1.57 & 64.50 & 1.10 & 33.35 & 0.60 & 25.63 & 0.41 & -2.58 & -0.06 \\
\hline edum2 & -20.25 & -0.87 & 7.62 & 0.34 & -0.25 & -0.01 & -2.35 & -0.10 & -23.38 & -1.37 \\
\hline edum3 & -40.52 & -1.50 & -23.35 & -0.89 & -19.19 & -0.77 & 1.35 & 0.05 & -34.77 & -1.72 \\
\hline edum4 & 24.88 & 0.67 & 10.00 & 0.28 & -7.25 & -0.22 & 2.52 & 0.07 & -8.76 & -0.32 \\
\hline edum5 & -45.71 & -0.92 & -105.51 & -2.01 & 52.42 & 1.03 & -59.91 & -1.05 & 50.00 & 1.22 \\
\hline scf1 & 35.42 & 0.98 & -21.13 & -0.59 & 45.30 & 1.33 & 13.87 & 0.36 & -20.23 & -0.73 \\
\hline scf2 & -26.61 & -0.68 & -39.84 & -1.09 & 16.09 & 0.46 & -35.83 & -0.91 & -39.28 & -1.39 \\
\hline scf3 & 3.48 & 0.09 & -14.54 & -0.41 & 54.04 & 1.60 & -8.17 & -0.21 & -17.59 & -0.64 \\
\hline scf4 & 48.57 & 1.32 & -26.15 & -0.77 & -5.10 & -0.16 & -33.93 & -0.92 & -50.05 & -1.91 \\
\hline scf5 & -40.52 & -0.36 & -126.76 & -1.31 & -62.11 & -0.67 & -210.18 & -2.00 & -92.57 & -1.22 \\
\hline scf6 & -8.04 & -0.16 & -11.94 & -0.24 & -6.65 & -0.14 & 58.96 & 1.09 & -40.51 & -1.05 \\
\hline scf7 & 75.57 & 1.60 & -69.89 & -1.49 & 48.65 & 1.09 & 7.80 & 0.15 & -16.74 & -0.46 \\
\hline $\mathrm{scm} 1$ & 43.82 & 1.06 & 5.47 & 0.13 & 30.65 & 0.76 & 8.29 & 0.18 & 60.27 & 1.83 \\
\hline $\mathrm{scm} 2$ & 6.40 & 0.23 & -10.18 & -0.36 & -21.04 & -0.78 & 33.62 & 1.10 & 24.54 & 1.13 \\
\hline $\mathrm{scm} 3$ & 36.00 & 1.15 & -20.49 & -0.73 & 8.06 & 0.30 & 27.76 & 0.91 & 17.30 & 0.80 \\
\hline $\mathrm{scm} 4$ & -13.55 & -0.52 & 2.16 & 0.09 & 17.69 & 0.76 & 21.48 & 0.81 & 20.33 & 1.07 \\
\hline scm5 & -84.03 & -1.94 & -35.60 & -0.79 & 58.94 & 1.37 & 17.41 & 0.36 & 66.45 & 1.90 \\
\hline scm6 & -34.35 & -0.82 & -96.35 & -2.19 & 35.57 & 0.84 & 34.47 & 0.72 & -3.40 & -0.10 \\
\hline $\mathrm{scm} 7$ & 7.32 & 0.20 & -59.79 & -1.86 & 5.09 & 0.17 & 41.32 & 1.18 & 32.36 & 1.30 \\
\hline yfa1 & -9.60 & -0.29 & -11.89 & -0.36 & -47.61 & -1.52 & 8.36 & 0.23 & 36.96 & 1.47 \\
\hline yfa2 & 73.49 & 0.88 & 84.48 & 1.31 & 11.40 & 0.19 & 14.54 & 0.21 & 16.03 & 0.32 \\
\hline yfa4 & -27.77 & -0.83 & 15.17 & 0.46 & -24.74 & -0.78 & 30.01 & 0.84 & 31.23 & 1.23 \\
\hline yfa5 & -16.78 & -0.52 & 10.83 & 0.34 & -21.09 & -0.69 & 21.68 & 0.63 & 25.25 & 1.03 \\
\hline yfa6 & 34.11 & 0.89 & -5.79 & -0.17 & -41.10 & -1.22 & -11.59 & -0.30 & 23.79 & 0.88 \\
\hline yfa7 & -7.61 & -0.18 & -57.82 & -1.53 & -36.85 & -1.02 & 16.76 & 0.41 & 11.68 & 0.40 \\
\hline yfa8 & -24.93 & -0.52 & 1.53 & 0.04 & -63.97 & -1.61 & -33.49 & -0.74 & 37.36 & 1.16 \\
\hline
\end{tabular}


continue table A3. Interval regression estimates for hours of self-study

\begin{tabular}{|c|c|c|c|c|c|c|c|c|c|c|}
\hline \multirow{3}{*}{ Variable } & \multirow{2}{*}{\multicolumn{2}{|c|}{ Law }} & \multirow{2}{*}{\multicolumn{2}{|c|}{ Mathematics }} & \multicolumn{2}{|c|}{ Course } & \multirow{2}{*}{\multicolumn{2}{|c|}{ Economics }} & \multirow{2}{*}{\multicolumn{2}{|c|}{ Ec. History }} \\
\hline & & & & & Accou & ting & & & & \\
\hline & coef. & t-val & coef. & t-val & coef. & $\mathrm{t}$-val & coef. & t-val & coef. & t-val \\
\hline ymo1 & 26.68 & 0.90 & 11.45 & 0.39 & 15.35 & 0.55 & -16.10 & -0.51 & 16.73 & 0.74 \\
\hline ymo2 & 0.75 & 0.02 & -21.90 & -0.73 & 16.48 & 0.57 & -23.19 & -0.71 & 36.87 & 1.59 \\
\hline ymo4 & 4.01 & 0.13 & -23.75 & -0.82 & -9.72 & -0.35 & -71.04 & -2.25 & 11.70 & 0.52 \\
\hline ymo5 & -11.37 & -0.38 & -1.41 & -0.05 & 12.25 & 0.45 & -48.99 & -1.56 & 17.35 & 0.78 \\
\hline ymo6 & -7.39 & -0.17 & -9.58 & -0.23 & -1.07 & -0.03 & -51.62 & -1.16 & 8.02 & 0.25 \\
\hline ymo7 & 28.01 & 0.54 & 13.43 & 0.30 & -31.98 & -0.75 & -55.77 & -1.14 & -46.20 & -1.34 \\
\hline female & 0.47 & 0.03 & 0.12 & 0.01 & 22.66 & 1.61 & -20.28 & -1.27 & 1.12 & 0.10 \\
\hline grade1 & 514.34 & 1.98 & -241.96 & -2.20 & 4.94 & 0.05 & 15.77 & 0.13 & -94.60 & -1.12 \\
\hline grade2 & -39.84 & -0.35 & -77.79 & -0.49 & -211.06 & -1.41 & 120.81 & 0.71 & -202.96 & -1.66 \\
\hline grade3 & -215.12 & -1.24 & -162.68 & -0.64 & -239.00 & -0.99 & -46.90 & -0.17 & -120.38 & -0.61 \\
\hline grade4 & 1.24 & 0.79 & -0.82 & -0.54 & -1.50 & -1.05 & 3.42 & 2.10 & -0.32 & -0.28 \\
\hline dummy d2 & -10.14 & -1.94 & 1.65 & 0.31 & 2.94 & 0.59 & 3.48 & 0.61 & 1.53 & 0.37 \\
\hline dummy d3 & 1.67 & 0.99 & 3.19 & 1.94 & -1.38 & -0.88 & 3.04 & 1.71 & 1.00 & 0.79 \\
\hline dummy d4 & 6.39 & 1.98 & 0.55 & 0.19 & 2.83 & 1.03 & 0.63 & 0.20 & 3.67 & 1.63 \\
\hline dom1 & 47.61 & 1.24 & 30.60 & 0.82 & -18.33 & -0.52 & -1.49 & -0.04 & 7.04 & 0.24 \\
\hline dom2 & 4.11 & 0.25 & 8.53 & 0.55 & 8.10 & 0.55 & -4.78 & -0.28 & -16.55 & -1.38 \\
\hline dom3 & -12.45 & -0.59 & 37.76 & 1.80 & 36.06 & 1.81 & 6.83 & 0.30 & -6.48 & -0.40 \\
\hline age & -32.33 & -2.58 & -19.05 & -3.13 & -17.26 & -2.98 & -16.00 & -2.42 & -10.91 & -2.32 \\
\hline constant & 749.83 & 3.00 & 587.18 & 3.93 & 545.38 & 3.85 & 319.52 & 1.97 & 312.29 & 2.71 \\
\hline N. obs. & 371 & & 371 & & 371 & & 371 & & 371 & \\
\hline LR-test* & 0.02 & & 0.03 & & 0.07 & & 0.31 & & 0.12 & \\
\hline
\end{tabular}

Note. ${ }^{*}$ p-values. The dependent variables is the number of hours of self-study. For the description of the explanatory variables see table A1. 